\title{
Analysis on Chinese Traditional Cultural Elements in Modern Logo Design
}

\author{
Xiaowei Zhang \\ Yantai Nanshan University \\ Longkou, Shandong, China \\ e-mail: 45821665@qq.com
}

\begin{abstract}
A logo is a symbolic communication mark which employs simple and concise images for the expression of specific connotation and the dissemination of specific information. Logo design is widely used for company's image advertising. Modern logo design is commonly inspired by Chinese traditional cultural elements and it incorporates them perfectly into the design subject to create designs with the charm of Chinese traditional culture. Modern logo design is critical both for the application of traditional cultural elements and the dynamic integration of traditional and modern design philosophies, so it is one of the important fields of research and investigation for modern logo designers to have a correct understanding of the relationship between Chinese traditional cultural elements and modern logo design so as to promote the extensive and in-depth application and transmission of Chinese traditional cultural elements in modern logo design.
\end{abstract}

Keywords-logo design; Chinese traditional culture; element; analysis

\section{Status Quo OF ChINA’s Logo Design}

\section{A. Connotation and Features of Logo Design}

Logo design is an important part of modern visual communication system and employs special graphs to represent figurative things, events, scenes, abstract spirit and ideas in order to foster customers' immediate association and brand recognition. In the arts field of visual communication, logo arts is committed to create graphic marks with high significance and complete artistry through an artistic process and comprehensive integration of patterns, symbols and colors of things familiar to the target groups. These symbols which are distinctive in image, artistry and common recognition have the features of frequent appearance, wide application, easy recognition and reinforced impression in the process of transmission of corporate image.

\section{B. Status Quo and Development Trend of China's Logo Design}

In recent years, the design concepts and aesthetic standards of Chinese logo designers have substantially changed with the continuous influence of a variety of new artistic design concepts and ideological trends. Although keeping pace with world development, our artistic design works have unknowingly gone away from the national tradition and gradually lost the right of discourse. In contrast, because some designers rely excessively on and overuse the traditional culture, the field of logo design is isolated and sluggish. It is the basic criteria of modern logo design to introduce new concepts and new methods, to follow the artistic rules of logo design, to appropriately add Chinese traditional cultural elements, to seek creative tools and techniques of artistic expression of logo design in order to represent the overall aesthetic feeling of modern logo design and to obtain the best visual effect.

The systematic research has clearly indicated that enterprise's core ideology, national cultural deposits and spirit of the time are mostly conveyed through the beauty in form of well-known logo design, so it has realistic significance for reference to gain inspiration from traditional culture and integrate the traditional cultural elements into the logo design.

\section{ANALYSIS ON THE APPLICATION OF CHINESE TRADitional CULTURAL ELEMENTS IN LOGO DESIGN}

\section{A. The Application of Chinese Traditional Figures in Logo Design}

China has a long cultural heritage and transmission of more than 5,000 years and creates brilliant and profound traditional culture. In remote antiquity, Chinese ancestors have already used graphs for emotional expression and communication. In the Neolithic Age, they used lines adorns colored pottery and stone inscription on rock cliff to record their life, which represents the earliest graphic arts in human history.

Chinese graphic arts originate earlier and maintain stable development and orderly transmission. It employs wealthy, simple and inspired design and evolves from taotie motif on bronze vessels from Shang and Zhou dynasties, then to tadpole script, plum blossom script during the Warring States period, to phoenix-shaped lacquer in the Han Dynasty, to lotus pattern on porcelain in Tang Dynasty and to the later bronze inscription. In the process of evolution and development, Chinese traditional graph shows diverse appearance, clear context and unified style, symbolizing the unique, profound and attractive national culture and connotation of national spirit. With the passage of time and transmission from generation to generation, the unique structural system of Chinese traditional arts has been established after continuous precipitation, extension and evolution of Chinese traditional graph, and this system 
embodies the wisdom of Chinese nation for thousands of years and represents the special artistic spirit of Chinese nation.

"Beijing 2008 Olympics Logo", designed by Chinese famous designer Mr. Chen Shaohua, can be said to be a classic modern logo design. This logo uses the typical colors of five Olympic rings, featuring a stylized traditional Chinese handicraft pattern known as "Chinese knot" and depicting someone doing "Tai Ji". The simple gesture lines symbolize the graceful, harmonious and dynamic movements that connote the unity of, cooperation among, exchange between and development for the peoples all over the world and portray the Olympic spirit of Citius, Altius, Fortius (for Swifter, Higher, Stronger). The overall structure of this logo employs the "endless knot", one of the Chinese traditional auspicious patterns, and what is precious is that the logo embodies the theme to its most appropriate extent and completes the perfect combination of Chinese tradition with the language of modern logo design through the freehand technique of traditional Chinese painting and calligraphy rather than direct utilization of the pattern.

Coincidentally, another famous logo of China - logo of China Unicom is also evolved from the ancient graphic pattern "endless knot". It comprises of four squares indicating accessibility from all directions and everything goes well, six rounds standing for interconnection and successful development and ten holes meaning perfection in everything. This logo is filled with long-lost auspiciousness of ancient orient based on either symmetry or even number.

China Unicom's logo has two obvious end-to-end heart shapes, clearly conveying the Unicom's purpose: communication and sincerity. China Unicom is closely linked with customers and committed to do everything for the sake of customers.

What belongs to the nation belongs to the world. The integration of Chinese traditional graphic elements into modern logo design is not only the demand for era development but a key to aid and promote Chinese enterprise's image advertising by using logo. The combination of traditional graphic element with modern logo design is not simple copinism, but an attempt to explore, change and extend the traditional graph which acts as inspiration and source of creation, so that modern logo design is full of vigor and vitality of Chinese traditional culture when the traditional graph is used as the starting point and innovation point of logo design.

\section{B. Application of Chinese Characters in Logo Design \\ 1) Origin and development of Chinese characters}

Chinese characters are one of the world's oldest languages. After a long historical development, Chinese characters were gradually mature and a complete Chinese characters system was established until the late Shang Dynasty of 3,000 years ago when oracle bone inscription was commonly and widely applied. Chinese characters was named as "Hanzi" for the first time in Han Dynasty through bronze inscription, small seal script and official script since the emergency of oracle bone inscription. During the subsequent periods, the name of "Hanzi" is still used today irrespective of the continuous change and evolution in font style. Hanzi is the main characters used continuously for the longest time in Chinese history and used as the main official writing system in past dynasties of China. Its evolution processes can be depicted as: The origin including carved symbols on the tortoise shell of Jiahu found 7762 years ago ( \pm 128 years), inscribed symbols in Shuangdun, symbols inscribed on pottery in Banpo, inscribed hieroglyphic found in Zhuangqiaofen, symbols carved on the pottery vessels in Dawenkou, Zhuwen in Taosi Site in era of Yao and Shun, Shui script in Xia Dynasty; the mature period includes symbols carved on animal bones (in late phase), oracle bone inscription, bronze inscription, large seal script, small seal script, Zhou graphs, official script, regular script, cursive script, running scripts, etc.. It is well known that Chinese characters have a three-in-one property of incorporating image, sound and speech, which is an exclusive property compared to other languages in the world, so Chinese characters have unique charm. Chinese characters are the cultural treasure of Han people for thousands of years and our lifelong mentor and spiritual homeland. It often evokes people's wonderful and audacious association and aesthetic experience.

\section{2) Application of Chinese characters in logo design}

Today, as a tool for worldwide information dissemination, words have been commonly used in logo design and have drawn increasing attention of logo designers. How to perfectly incorporate words into a logo without weakening the unique charm of words has always been the target of designers. Chinese characters are is the root of Chinese civilization, and carries rich cultural accumulation and splendid civilization. As a visual symbol for communication, Chinese characters play an important role in society. We should make good use of the unique language and symbol of Chinese characters, design and restructure them in a new way in order to show the in-depth research on Chinese culture and spiritual pursuit in Chinese art design, which has important realistic significance on the exploration and design research of Chinese characters. When Chinese characters are employed as logo design elements, we should research not only the historical development, but the advantages of Chinese characters as a logo element, what's more, a delicate and intensive research should be carried out for the fonts, meanings, forms of calligraphy, forms of seal engraving, design techniques of Chinese characters, only in this way, can Chinese characters shine brilliantly in the field of logo design indeed.

Although the ancient Chinese characters have evolved through millennium, its vigor and unique artistic charm remain unabated. Chinese characters have the "pictographic" and "symbolic" property, so they themselves are the most primitive form of logo to some extent. In addition, oracle bone inscription, seal script, clerical script, running script, cursive script and other various calligraphy styles also provide modern logo with a wealth of visual elements and inspiration for creation via their different representations. As exemplified in the logo of Shandong TV Station in China, Shandong is located in the lower reach of Yellow River, and therefore, the station logo is designed as a transformation of " $\mathrm{S}$ ", the initial of Shandong, which wriggles like the meandering Yellow River, presenting strong regional characteristic. What's more important, the station logo features "山" (in English: mountain) in the cursive script on the whole and is shaped like a colorful 
ribbon, embodying the hospitality of Shandong people. Shandong TV station's logo becomes a classic design of the application of Chinese characters in cursive script in logo design.

Another classic design is the emblem of Beijing 2008 Olympic Games. The logo employs one of Chinese traditional cultural elements - Chinese seal as the background, which is an undoubted major breakthrough and innovation in the design history of Olympic emblem. The ancient seal carries the solemn commitment to "Green Olympics, High-tech Olympics and People's Olympics" made by the great nation featuring the tradition of integrity for several thousands of years. The Chinese character "京" (pinyin: Jing) in seal script emphasizes that Beijing, an ancient capital bursting with youthful energy, is open and all-embracing in the cultural cohesion to welcome people of all nationalities in the world. The character cut in intaglio uses simple lines to sketch a dancing athlete running at a full speed to embrace the victory, and the whole logo represents the high combination of strength and beauty and embodies the perfect interpretation of sportsmanship.

\section{Application of Chinese Auspicious Cultural Elements in Logo Design}

\section{1) Formation of Chinese auspicious culture}

Auspicious culture, an important part of Chinese traditional culture, reflects people's simple wish and the nation's cultural psychology for the pursuit of happiness, luck and well-being. In China, auspicious symbols and graphs can be found everywhere, and auspicious awareness and auspicious culture have been deeply rooted in Chinese people's life to the extent that people believe all good things can be found in auspicious culture and constitute the eternal theme of auspicious culture. Auspicious culture is created when people want to express their wishes for happiness, goodness and peace.

The ancient Chinese people's sense of insecurity towards life gives rise to the awareness about the pursuit of happiness and prayer for auspiciousness and peace, and the awareness about auspiciousness limits the choice of auspicious symbols for the ancient people. In the era of extreme shortage of technology and civilization, Chinese ancestors were very confused about and feared of diseases, pestilence and death, so it was urgent to create the spiritual pillar for people to expel demons and ghosts, eliminate disasters and terminate misfortunes, and totem emerged in response. From a certain perspective, the totem is human beings' first mascot. From the reverence for life to the later worship of animals, plants and celestial bodies, these figurative or abstract things have gradually evolved into mascots standing for confidence, power and hope.

With the historical development, the auspicious culture has extended to all aspects of people's basic necessities from the tribal totem in terms of its external expression; its inherent connotation is not only a simple and intuitive wish, but sublimated to the culture forecasting luck, happiness, longevity, wealth, promotion and many children, creating the unique auspicious culture in the field of national culture.

2) Application of Chinese auspicious cultural elements in logo design
The optimism spirit and good connotation of Chinese auspicious cultural symbols have a great effect on the pattern representation and theme selection of modern logo design. Auspicious elements are commonly used in modern logo design. Modern logo design selectively adopts and transforms the traditional auspicious patterns through replacement, deconstruction, reconstruction, symbolization, simplification and other techniques, and it combines Chinese traditional aesthetics with the international aesthetic sense and features unique type and distinctive style, so that the logo not only conforms to the aesthetic habits of modern design but conveys national characteristic. Chinese traditional auspicious culture has been penetrated into various patterns of manifestation through symbolization, homophone and ideograph techniques, and thus it can be seen that the involvement of auspicious elements enriches the cultural connotation of modern design.

As exemplified in the logo of Phoenix Hong Kong Channel, it is evolved from Taijitu (literally "diagram of the supreme ultimate") on the whole. Since ancient times, Chinese people have regarded phoenix as the symbol of luck, happiness, peace and well-being, and phoenix represents the national discourse in the tradition. However, the male phoenix and female phoenix representing Yang and Yin respectively, Phoenix Channel has found a delicate balance between the eastern and western ideologies, and based on this, the logo of Phoenix Channel comprises of two rotated birds inside a circle, and all the ports are open rather than closed, leaving an opening of Chinese traditional and isolated ideology and conveying an open media attitude of Phoenix Channel.

Two phoenixes in the logo of Phoenix Channel form a round shape encircling an eye looking at the world. The color tone is yellow color symbolizing nobility and elegance and the complementary color is warm and bright red color, and these two colors are Chinese people's favorite colors featuring auspiciousness. Naming and logo of Phoenix Channel convey integration, openness and communication with "harmony" as the core. "Harmony" is not only the core concept of Chinese culture, but one of the essences of phoenix culture. Chinese people have attached great importance on "harmony" in the pursuit of harmonization, modesty, harmony, reconciliation and peaceful coexistence. The transmission and development of Chinese culture for several thousands of years is a result of cultural integration of all nations and regions. The female phoenix and male phoenix representing Yin and Yang respectively look like two burning flames which are visually integrated to form a circle in dynamic motion, marking the historic integrative recombination of eastern and western cultures and traditional and modern cultures.

Another well-known case refers to the logo of China's Civil Aviation. Likewise, it employs a flying phoenix, featuring the beauty of motion in quiescence and embodying China's Civil Aviation's persistence, and the background color uses bright and pure China red to express people's good wishes for celebration, peace and good luck.

As can be seen from the analysis on the above cases, auspicious elements are commonly used in modern logo design. Modern logo design selectively adopts and transforms the traditional auspicious patterns through replacement, 
deconstruction, reconstruction, symbolization, simplification and other techniques, and it combines Chinese traditional aesthetics with the international aesthetic sense and features unique type and distinctive style, so that the logo not only conforms to the aesthetic habits of modern design but conveys national characteristic.

\section{Application of Chinese Paper Cutting Art in Modern Logo Design}

Folk paper cutting is an art form with a certain range of application and popularity created to meet laboring people's demand for mental life. Paper cutting is a graphic art developed from symbolic marks and its most important feature lies in the emotional expression. A variety of geographical and cultural phenomena are commonly used as the theme of paper cutting to present an artistic and representative silhouette and then to convey good wishes. Objectively speaking, Chinese folk paper cutting is a cultural phenomenon of tangible inheritance, involving not only the inheritance of its pattern, but the inheritance of its own unique underlying connotation.

From the perspective of techniques, paper cutting involves making small cuts into paper to create the desired image. Artists have developed various techniques centering on cutting, engraving and hollowing to enrich and diversify the presentation of paper cutting. They have learned from longterm artistic and life practice and used their intelligence and wisdom to extract and utilize the traditional elements based on their understanding of manifestation mode of traditional paper cutting, so that era characteristic is added to paper cutting.

Many signs of traditional paper cutting can be found from modern logo. Logo designers tend to abstract and add new connotation to the animal images with symbolic significance and historical origin, and then transform the original image, making ancient things serve the present. As exemplified in the design logo of Bank of China, the designer Mr. Kan Tai-keung makes full use of traditional cultural connotation of paper cutting: hemispherical dome. The ancient coin carrying the concept of hemispherical dome indicates that Bank of China is major globally-oriented international bank. Apparently, the logo of Bank of China is inspired by the ancient coin tied with a red string, and the square hole in the coin and the red string constitute the character of "中", carrying strong national characteristics. The logo design of Bank of China is a perfect embodiment of the feature "it is foremost to establish an idea, and then transform the idea into a design" of Chinese traditional art and paper cutting art.

\section{CONCLUSION}

China has a long history and profound and brilliant traditional culture in various forms, which provide inexhaustible valuable artistic treasure for modern logo designers in the process of design. Since not all of the elements are appropriate for a specific logo design, it is far from a simple combination of modern logo design with traditional cultural elements. Furthermore, Chinese traditional culture has a long development history and carries not only the trace of age of ignorance and age of barbarism, but also the sign of several thousand years of feudal society, and therefore, some traditional cultural elements have superstitions and outdated dross and lose their reference value.

During the application of traditional cultural elements in modern logo design, we must have a realistic and pragmatic attitude and attempt to eliminate the false and retain the true for the promotion and inheritance of unique, regional and national characteristics of traditional culture. In the process of logo design, we should fully exploit and learn the essence of various traditional elements instead of mechanical application, indiscriminate copy and processing, only in this way can the spiritual characteristic of traditional cultural element be fully embodied in modern logo design, helping promote China's modern logo design to a higher level of development and innovation.

\section{REFERENCES}

[1] Liu Wen. Application of Traditional Chinese Graphs in Modern Logo Design [J], Chongqing University of Science and Technology (Social Science), 2010,02

[2] Lu Zhongyuan, Peng Niansheng. Creative Chinese Logo: Special Edition for Commercial Logo 1 [M] Wuhan: Hubei Fine Arts Publishing House, 2001.01

[3] Guo Younan. Emotional Logo [J]. Arts Exploration, 2005,08

[4] Wang Nanming Calligraphy Open to the World [J] Study of Calligraphy. Total No. 51

[5] Ye Guoqiang Charm of Traditional Culture in Logo Design [J]. Arts Exploration, 2006.04

[6] Xu Zhimin. Folk Paper Cutting [M]. Beijing: China Light Industry Press, 2004.09 